Published in final edited form as:

Nature. 2019 January ; 565(7739): 343-346. doi:10.1038/s41586-018-0835-2.

\title{
Photoredox Catalysis Using Infrared Light via Triplet Fusion Upconversion
}

\author{
Benjamin D. Ravetz ${ }^{\# 1}$, Andrew B. Pun ${ }^{\# 1}$, Emily M. Churchill ${ }^{1}$, Daniel N. Congreve ${ }^{2,{ }^{*} \text {, }}$ \\ Tomislav Rovis ${ }^{1,{ }^{*}}$, and Luis M. Campos ${ }^{1,{ }^{*}}$ \\ ${ }^{1}$ Department of Chemistry, Columbia University, New York, NY, 10027, USA \\ ${ }^{2}$ Rowland Institute at Harvard University, Cambridge, MA, 02142, USA \\ \# These authors contributed equally to this work.
}

\begin{abstract}
Recent advances in photoredox catalysis have made it possible to execute a multitude of challenging synthetic transformations, polymerizations, and surface modifications ${ }^{1,2,3}$. In all cases, these transformations require ultraviolet or visible light stimuli. The use of visible light irradiation has intrinsic challenges. For example, the penetration of visible light is very low through most reaction media, leading to problems in large scale reactions. Moreover, reactants can compete with the photocatalysts for incident light absorption, limiting scope. Near infrared (NIR) radiation can overcome many of these fundamental problems. NIR light is known to have a much higher penetration depth through a variety of media, notably biological tissue ${ }^{4}$. Here, we demonstrate a variety of photoredox transformations under infrared radiation by utilizing the photophysical process of triplet fusion upconversion. This generates molecules in their singlet excited state that can perform single electron transfer (SET), serving as photocatalysts or photoinitiators. We illustrate that this is a general strategy applicable to a wide range of photoredox reactions. We tune the upconversion components to adjust the output light, accessing both orange light and blue light from low-energy infrared (IR) light, by pair-wise manipulation of the sensitizer and annihilator. We further demonstrate that the annihilator itself can be used as a photocatalyst, simplifying the reaction. This approach allows us to execute catalysis through several barriers that are impenetrable by visible light, expanding the landscape of photocatalysis to a variety of new materials and environments. The results demonstrated here allow high-energy transformations from low-energy IR light with all the benefits that the latter affords.
\end{abstract}

Users may view, print, copy, and download text and data-mine the content in such documents, for the purposes of academic research, subject always to the full Conditions of use:http://www.nature.com/authors/editorial_policies/license.html\#termsReprints and permissions information is available at www.nature.com/reprints. A provisional patent has been filed on this technology by the institutions on behalf of the authors of this work.

*Corresponding author: 1c2730@columbia.edu; tr2504@ columbia.edu; congreve@ rowland.harvard.edu. Author Contributions: ABP and DNC carried out the upconversion experiments. BDR, ABP and EMC performed and analyzed the photoredox and materials penetration experiments. DNC, TR, and LMC initiated and directed the study, and wrote the manuscript with contributions from all authors.

Supplementary Information is available in the online version of this paper.

Online Content. Methods, along with additional Extended Data are available in the online version of the paper.

Data Availability. The data that support the findings of this study are available from the corresponding authors on reasonable request. 
Current photocatalysts must be excited with either UV or visible light, translating to an initial excited state energy between $\sim 50-80 \mathrm{kcal} / \mathrm{mol}^{5,6}$. This energy is then transferred to the substrate of interest, leading to the desired reactivity. NIR light can only generate low energy excited states ( $\sim 35 \mathrm{kcal} / \mathrm{mol})$, which falls short of the energy required to achieve the majority of desired transformations.

The photophysical process of triplet fusion (TF) upconversion, the conversion of low-energy photons into high-energy excited states, has seen a surge of attention in recent years ${ }^{7}$ in large part due to its potential to increase the efficiency of photovoltaics. ${ }^{8}$ While the solar applications of TF upconversion have been given the most attention, it can be used in a variety of other applications ranging from biological imaging ${ }^{9}$ to data storage. ${ }^{10}$

Upconversion via TF or using lanthanide-containing nanoparticles can harness NIR light for chemical transformations, but these are limited to the direct activation of substrates. 11,12,13,14 This shortcoming can be addressed by activation of catalyst in lieu of substrate. Organic chromophores have great potential for TF upconversion, especially because of their tunable electronic structure. ${ }^{15}$ (Fig. 1A). We show that it is possible to use low-energy NIR light to access the complex synthetic toolbox enabled by photoredox catalysis. This strategy is highly modular, as it is possible to match components of the upconversion and photoredox systems to promote a variety of chemical transformations in one pot. ${ }^{16,17}$

The process of TF upconversion involves two species: an annihilator and a sensitizer (Fig 1B) ${ }^{18,19}$. The sensitizer absorbs a low energy photon, which initially generates a singlet excited sensitizer $\left({ }^{1}[\mathrm{Sen}]^{*}\right)$ which decays into a triplet excited sensitizer $\left({ }^{3}[\mathrm{Sen}]^{*}\right)$. This energy is then transferred to the annihilators, forming $\left({ }^{3}[\mathrm{An}]^{*}\right)$. Two $\left({ }^{3}[\mathrm{An}]^{*}\right)$ molecules can then undergo TF which leads to the generation of a higher energy singlet exciton on one of the annihilators $\left({ }^{1}[\mathrm{An}]^{*}\right)$ which then decays via fluorescence, giving off a high energy photon.

In considering the energetic requirements of a new IR-visible TF upconversion system, we became aware of the recent work of Wasielewski and coworkers who showed it is possible to vary the singlet energy levels of diketopyrrolopyrrole (DPP) derivatives for singlet fission without altering the triplet energy. ${ }^{20}$ We leveraged this finding to adjust the singlet energy until it was slightly less than double the triplet energy. This led us to observe TF upconversion. We used FDPP as an annihilator with PdPc as the sensitizer ${ }^{21}$, absorbing NIR photons of $730 \mathrm{~nm}$, with an emission that extends to $~ 530 \mathrm{~nm}$ (Fig. 1C). The FDPP:PdPc system has an upconversion yield of $3.2 \%$, while the fluorescence quantum yields of common photoredox catalysts such as $\left[\mathrm{Ru}(\mathrm{bpy})_{3}\right]^{2+}$ and Rose Bengal are $9.5 \% \mathrm{v}$ and $9 \% \mathrm{ii}$ respectively (see SI, page S16, for full details). When combining the upconversion system with the hydrodehalogenation conditions ${ }^{22}$, we observed the dehalogenated product in $61 \%$ yield (Fig. 2A). In this initial example, we established the ability of TF upconversion to enable low energy NIR light to activate a catalyst, Eosin Y, capable of reducing a $\mathrm{C}-\mathrm{Br}$ bond. Control reactions when the photocatalyst or upconversion components are removed show only trace yields. These results suggest the external NIR radiation is converted to visible light inside the reaction vessel, which is then absorbed by Eosin Y. As a direct comparison to blue light, the identical reaction was irradiated with a $40 \mathrm{~W}$ blue Kessil lamp, 
which provided a 78\% yield in similar reaction time. It is notable that the $0.040 \mathrm{~W}$ NIR diode is orders of magnitude weaker than the blue light source. We thus envision that the emitted light from upconversion is generated deep within the reaction vessel, leading to a large number of "lightbulbs" inside the flask. In turn, the net surface area of illumination by these lightbulbs is orders of magnitude in excess of what is possible with light sources on the outside. For this reason, we can maintain similar yields with a light source 1000 times less powerful than the photoredox standard.

To test the generality of this system towards other reactions, we pursued two other transformations. In similar fashion, Rose Bengal can be excited by NIR light TF upconversion to catalyze amine oxidation in $72 \%$ yield (Fig. $2 \mathrm{~B}$ ) ${ }^{23}$ Further, this system was adapted to an Eosin $\mathrm{Y}$ catalyzed $\mathrm{C}-\mathrm{N}$ bond activation, yielding phenanthridine products (Fig. 2C). ${ }^{24}$

With this FDPP:PdPc system, it is possible to use NIR light to promote reactions which require photocatalysts that absorb green or yellow light, but most organometallic photocatalysts absorb higher energy blue or UV light ${ }^{\text {iv }}$. We found that it is possible to use NIR absorbing sensitizer, Platinum (II) tetraphenyltetranaphthoporphyrin (PtTPTNP) 25,26 together with a simple blue emitting annihilator, TTBP, to generate NIR-to-blue photon upconversion, with an upconversion yield as high as $2.0 \%$ (Fig. 1D)(see SI, page S16, for full details). This novel system generates a large anti-Stokes shift $(\sim 1.0 \mathrm{eV}) .{ }^{27}$

We adapted this upconversion system to a prototypical $\left[\mathrm{Ru}(\mathrm{bpy})_{3}\right]^{2+}$ catalyzed reaction, the intramolecular [2+2] cyclization of enones (Fig. 2D). ${ }^{28}$ Adding TTBP and PtTPTNP to the standard reaction conditions provides cyclobutane product in moderate yield and excellent diastereomeric ratio. Control reactions revealed that the removal of $\mathrm{Ru}(\mathrm{bpy})_{3}\left(\mathrm{PF}_{6}\right)_{2}$ still results in a 38\% yield of cyclobutane product, suggesting that TTBP's ${ }^{1}[\mathrm{An}] *$ is capable of performing photoredox catalysis on its own, which reduces the 3-component system to a 2component system and streamlines catalysis.

To test if the ${ }^{1}[\mathrm{An}] *$ TTBP could be applied directly to catalysis, we chose to investigate the photoredox catalyzed cyclization of dienyl azides to pyrroles (Fig. 2E). Upon NIR (730 nm) irradiation of the sensitizer, annihilator, and substrate, the pyrrole product is formed in $80 \%$ yield.

After observing the strong reducing nature of TTBP's ${ }^{1}[\mathrm{An}]^{*}$ state, we attempted to use NIR radiation to initiate the polymerization of methyl methacrylate (MMA) via $\mathrm{C}-\mathrm{Br}$ bond reduction (Fig. 2F). Simply irradiating the sensitizer, annihilator, and initiator in neat MMA provided PMMA ( $M \mathrm{n}=46,000 \mathrm{~g} / \mathrm{mol}, D=1.80)$. The polymerization of MMA has been demonstrated with perylene as a photocatalyst under visible light irradiation ${ }^{29}$; however, we have allowed deep penetrating NIR light to stimulate the photocatalyst providing avenues to integrate photoredox catalysis into new materials.

To demonstrate the ability of NIR light to penetrate a variety of media, we performed the MMA polymerization with 5\% ethylene glycol dimethacrylate as a crosslinker to generate a freestanding gel while using several visible-light-absorbing materials to disrupt the path of the incident laser (Fig. 3A and3C). A PMMA gel was synthesized with a NIR light source 
through a variety of barriers; meanwhile, a gel was not formed when the $450 \mathrm{~nm}$ blue light source was used, presumably due to its limited penetrating ability (Fig. 3B). Notably, the NIR displayed excellent penetrating power through hemoglobin, the visible-light-absorbing species found in human blood. In addition to the gelation reaction, the [2+2] in Fig. 2D was performed through a barrier of $0.2 \mathrm{mM}$ hemoglobin solution. The product yield with the NIR laser is $46 \%$, identical to the reaction conducted without a barrier, while the blue laser provides $1 \%$ yield.

Visible-light photoredox scale-up suffers from shallow light absoption as evidenced by slow reaction rates. Also, increasing reaction-vessel size decreases relative surface area which reduces photon exposure ${ }^{\mathrm{iii}, 30}$, fundamentally limiting photocatalyst excitation. Infrared photoredox can overcome both of these challenges. For example, the IR penetration through the [2+2] reaction mixture (Fig. 2D) is 304-fold deeper than blue light based on concentration and extinction coefficients. (Fig. 4) By the same analysis, we found IR light penetrates 293 times further than blue light through the polymerization reaction mixture (Fig. 2F), which renders this chemistry scalable (Fig. 3D). This reaction also demonstrates that a laser is not necessary to perform upconversion, suggesting the broad applicability of this technique. Scalability and improved material penetration is shown by performing a multigram scale polymerization in an opaque silicone mold (Fig. 3E). The sealed mold is resistant to visible light; meanwhile, the NIR photons pass through uninhibited. As predicted, the defined shapes are only achieved with the NIR lamp and not with the blue lamp. With this proof-of-principle experiment it is possible to observe the impact of barrier penetration, and studies to characterize materials properties of various gels will follow.

\section{Supplementary Material}

Refer to Web version on PubMed Central for supplementary material.

\section{Acknowledgments:}

LMC thanks the National Science Foundation (NSF CAREER DMR-1351293) for funding. ABP thanks the NSF GRFP (DGE-16-44869). DNC is supported by the Rowland Fellowship at the Rowland Institute at Harvard. TR thanks NIGMS (GM125206).

\section{References}

1. Prier CK, Rankic DA \& MacMillan DWC Visible light photoredox catalysis with transition metal complexes: applications in organic synthesis. Chem. Rev 113, 5322-5363 (2013). [PubMed: 23509883]

2. Romero NA \& Nicewicz DA Organic Photoredox Catalysis. Chem. Rev 116, 10075-10166 (2016). [PubMed: 27285582]

3. Cambié D, Bottecchia C, Straathof NJW, Hessel V \& Noël T Applications of continuous-flow photochemistry in organic synthesis, material science, and water treatment. Chem. Rev 116, 1027610341 (2016). [PubMed: 26935706]

4. Smith AM, Mancini MC \& Nie S Second window for in vivo imaging. Nat. Nanotechnol 4, 710 (2009). [PubMed: 19898521]

5. Arias-Rotondo DM \& McCusker JK The photophysics of photoredox catalysis: a roadmap for catalyst design. Chem. Soc. Rev 45, 5803-5820 (2016). [PubMed: 27711624]

6. Le $\mathrm{C}$ et al., A general small-scale reactor to enable standardization and acceleration of photocatalytic reactions. ACS Cent. Sci 3, 647-653 (2017). [PubMed: 28691077] 
7. Zhou J, Liu Q, Feng W, Sun Y \& Li F Upconversion Luminescent Materials: Advances and Applications. Chem. Rev 115, 395-465 (2015). [PubMed: 25492128]

8. Schulze TF \& Schmidt TW Photochemical upconversion: present status and prospects for its application to solar energy conversion. Energy Environ. Sci 8, 103-125 (2015).

9. Il Park Y, Lee KT, Suh YD \& Hyeon T Upconverting nanoparticles: a versatile platform for widefield two-photon microscopy and multi-modal in vivo imaging. Chem. Soc. Rev 44, 1302-1317 (2015). [PubMed: 25042637]

10. Zhou Y et al., An upconverted photonic nonvolatile memory. Nat. Commun 5, 4720 (2014). [PubMed: 25144762]

11. Viger ML, Grossman M, Fomina N \& Almutairi A Low Power Upconverted Near-IR Light for Efficient Polymeric Nanoparticle Degradation and Cargo Release. Adv. Mater 25, 3733-3738 (2013). [PubMed: 23722298]

12. He S et al., Ultralow-intensity near-infrared light induces drug delivery by upconverting nanoparticles. Chem. Commun 51, 431-434 (2015).

13. Chen Z, Sun W, Butt H-J \& Wu S Upconverting-nanoparticle-assisted photochemistry induced by low-intensity near-infrared light: how low can we go? Chem. - A Eur. J 21, 9165-9170 (2015).

14. Askes SHC, Bahreman A \& Bonnet S Activation of a photodissociative ruthenium complex by triplet-triplet annihilation upconversion in liposomes. Angew. Chem. Int. Ed 53, 1029-1033 (2014).

15. Mahboub M, Huang Z \& Tang ML, Efficient infrared-to-visible upconversion with subsolar irradiance. Nano Lett 16, 7169-7175 (2016). [PubMed: 27788577]

16. Majek M, Faltermeier U, Dick B, Pérez-Ruiz R \& Jacobi von Wangelin A Application of visibleto-UV photon upconversion to photoredox catalysis: the activation of aryl bromides. Chem. Eur. $\mathrm{J}$ 21, 15496-15501 (2015). [PubMed: 26368791]

17. Häring M, Pérez-Ruiz R, Jacobi von Wangelin A \& Díaz DD Intragel photoreduction of aryl halides by green-to-blue upconversion under aerobic conditions. Chem. Commun 51, 16848 16851, (2015).

18. Singh-Rachford TN \& Castellano FN Low power visible-to-UV upconversion. J. Phys. Chem. A 113, 5912-5917 (2009). [PubMed: 19388680]

19. Singh-Rachford TN \& Castellano FN, Photon upconversion based on sensitized triplet-triplet annihilation. Coord. Chem. Rev 254, 2560-2573 (2010).

20. Hartnett PE et al., Effects of crystal morphology on singlet exciton fission in diketopyrrolopyrrole thin films. J. Phys. Chem. B 120, 1357-1366 (2016). [PubMed: 26820909]

21. Singh-Rachford TN \& Castellano FN Pd(II) Phthalocyanine-sensitized triplet-triplet annihilation from rubrene. J. Phys. Chem. A 112, 3550-3556 (2008). [PubMed: 18336014]

22. Neumann M, Füldner S, König B \& Zeitler K Metal-Free, Cooperative asymmetric organophotoredox catalysis with visible light. Angew. Chem. Int. Ed 50, 951-954 (2011).

23. Mashraqui SH \& Kellogg RM 3-Methyl-2,3-dihydrobenzothiazoles as reducing agent. Dye enhanced photoreactions. Tetrahedron Lett 26, 1453-1456 (1985).

24. Natarajan P, Kumar N \& Sharma M Visible light-mediated intramolecular C-H arylation of diazonium salts of $\mathrm{N}$-(2-aminoaryl)benzoimines: a facile synthesis of 6-arylphenanthridines. Org. Chem. Front 3, 1265-1270 (2016).

25. Sommer JR et al., Photophysical Properties of Near-Infrared Phosphorescent $\pi$-Extended Platinum Porphyrins. Chem. Mater 23, 5296-5304 (2011).

26. Deng F, Sommer JR, Myahkostupov M, Schanze KS \& Castellano FN Near-IR phosphorescent metalloporphyrin as a photochemical upconversion sensitizer. Chem. Commun 49, 7406-7408 (2013).

27. Sasaki Y, Amemori S, Kouno H, Yanai N \& Kimizuka N Near infrared-to-blue photon upconversion by exploiting direct S-T absorption of a molecular sensitizer. J. Mater. Chem C 5, 5063-5067 (2017).

28. Ischay MA, Anzovino ME, Du J, Yoon TP Efficient visible light photocatalysis of [2+2] enone cycloadditions. J. Am. Chem. Soc 130, 12886-12887 (2008). [PubMed: 18767798] 
29. Miyake GM \& Theriot JC Perylene as an organic photocatalyst for the radical polymerization of functionalized vinyl monomers through oxidative quenching with alkyl bromides and visible light. Macromolecules. 47, 8255-8261 (2014).

30. Tucker JW, Zhuang Y, Jamison TF \& Stephenson CRJ Visible-light photoredox catalysis in flow. Angew. Chem. Int. Ed 51, 4144-4147, (2012). 


\section{A. Infrared Photoredox Catalysis via TF Upconversion}

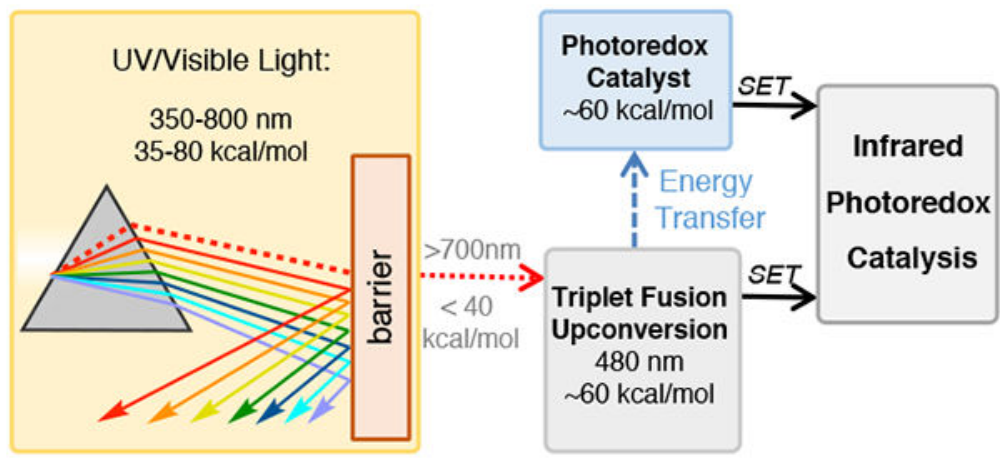

\section{B. TF Upconversion for Photoredox Catalysis}

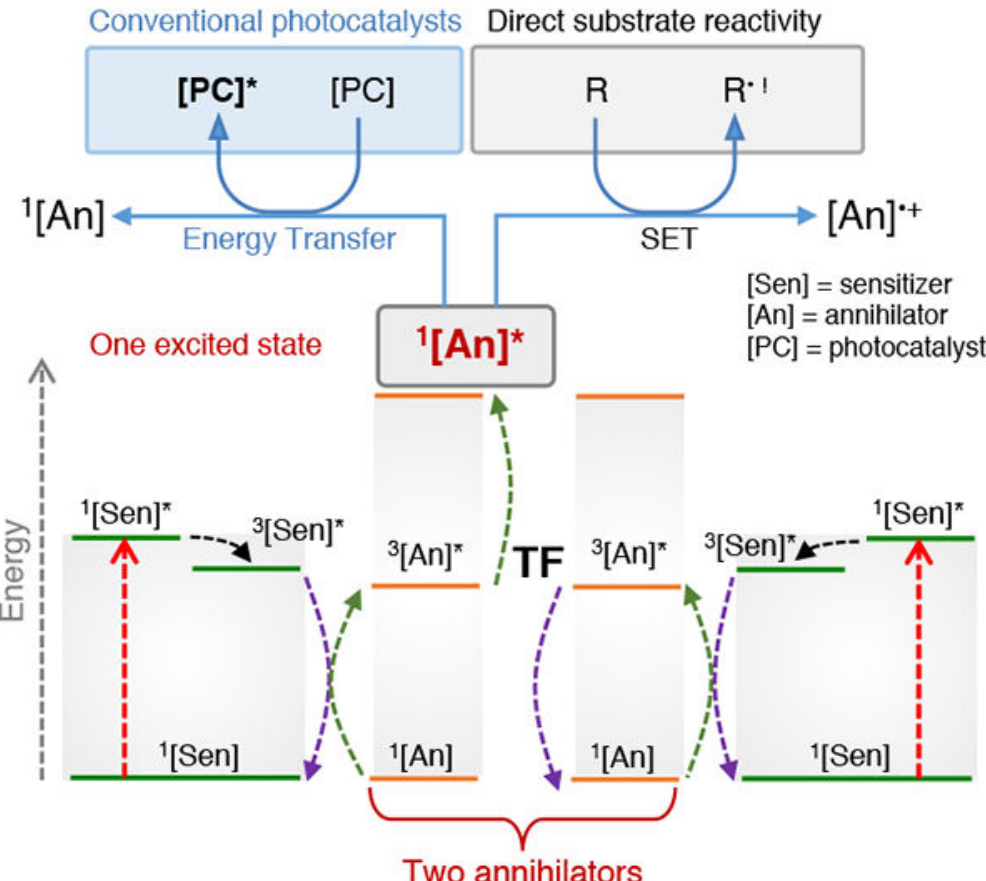

C. NIR-to-Orange TF Upconversion
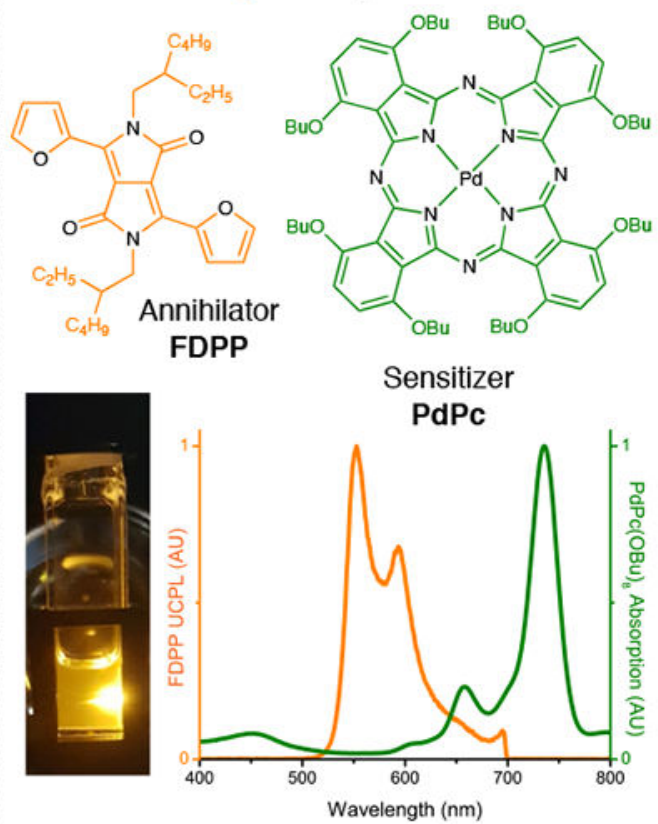

D. NIR-to-Blue TF Upconversion
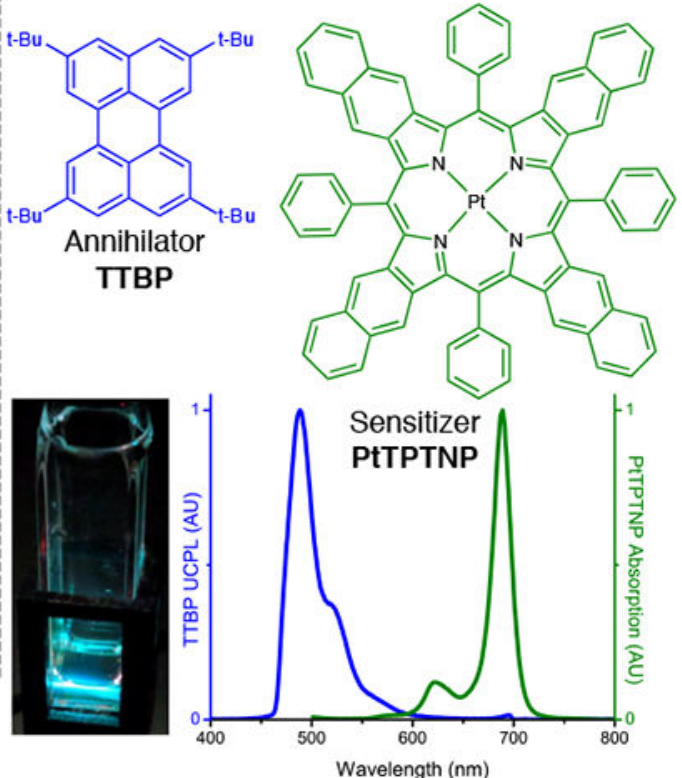

Figure 1. Upconversion design for NIR to orange and NIR to blue.

(A) A schematic of infrared photoredox catalysis via triplet fusion upconversion. SET, single electron transfer. $(\boldsymbol{B})$ A Jablonski description of triplet fusion upconversion and its adaptation to photoredox catalysis. Sen, sensitizer; An, Annihilator; PC, Photocatalyst (energy transfer from ${ }^{1}[\mathrm{An}]^{*}$ to PC may be by resonance transfer or photon emission/ absorbance). ( $\boldsymbol{C}$ ) NIR-to-orange upconversion photoluminescence using FDPP and PdPc, FDPP, furanyldiketopyrrolopyrrole; PdPc, Palladium (II) octabutoxyphthalocyanine. (D) 
NIR-to-blue upconversion photoluminescence using TTBP and PtTPTNP. PtTPTNP, Platinum (II) tetranaphthoporphyrin; TTBP, tetratertbutylperylene. 
NIR to Orange

Upconversion

A. Hydrodehalogenation

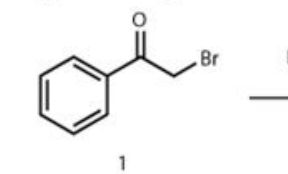

Eosin Y (S moty) DIPEA (2 eq.), FDPP ( 3 molo PdPc (0.15 mol\%), Diludine

$\mathrm{DMF} / \mathrm{MeCN} / \mathrm{PhCF}_{3}$ NIR diode, $12 \mathrm{~h}, 21^{\circ} \mathrm{C}$ $78 \%$ w/ 40 W Blue lamp (8h)

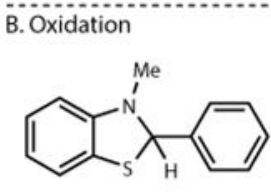

3

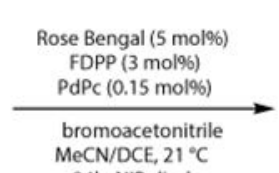

C. Radical cyclization<smiles>Nc1ccccc1N=C(c1ccccc1)c1ccccc1</smiles>
5
EOsin $Y(3$ mol\%), tBuONO

$\mathrm{DMSO}_{\mathrm{PhCF}}$ NIR diode, $8 \mathrm{~h}, 21^{\circ} \mathrm{C}$ FDPP (3 mol\%), PdPc (0.1 mol\%)

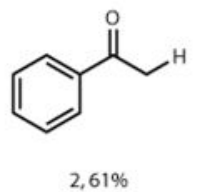

$2,61 \%$ $\mathrm{Br}^{-} \mathrm{Me}$

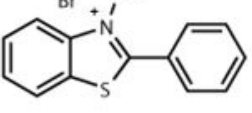

$4,72 \%$

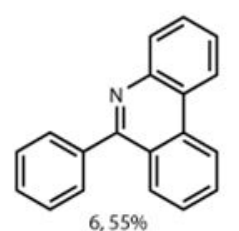

NIR to Blue

Upconversion

D [2+2] Cyclization

$\mathrm{Ph} \longrightarrow \mathrm{O} \quad \mathrm{O} P \mathrm{Ph}(\mathrm{bpy})_{3}\left(\mathrm{PF}_{6}\right)_{2}(5 \mathrm{~mol} \%)$

DIPEA (2 eq.), $\mathrm{LiBF}_{4}(2 \mathrm{eq}$ PTTPTNP $(0.12 \mathrm{~mol} \%)$

TTBP (10 mol\%)

$\mathrm{MeCN} / \mathrm{PhCF}_{3}$

NIR diode, $10 \mathrm{~h}, 21^{\circ} \mathrm{C}$

E. Vinyl Azide Sensitization

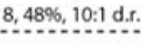

$8,48 \%, 10: 1$ d.r.

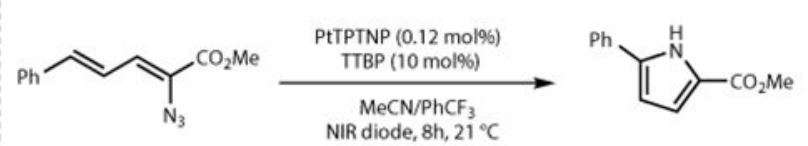

9

F. Radical Polymerization
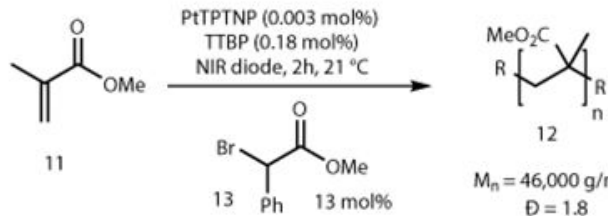

12

$M_{n}=46,000 \mathrm{~g} / \mathrm{mo}$ $\mathrm{D}=1.8$

Figure 2. Select examples of reactions driven by NIR light.

(A) Hydrodehalogenation reaction catalyzed by Eosin Y. (B) Rose Bengal catalyzed amine oxidation. $(\boldsymbol{C})$ Reductive radical cyclization yielding phenanthridine product. $(\boldsymbol{D})$

Intramolecular [2+2] cyclization. $(\boldsymbol{E})$ Pyrrole formation via vinyl azide reduction. $(\boldsymbol{F})$

Polymerization of methyl methacrylate. 


\begin{tabular}{|c|c|c|}
\hline A & $\begin{array}{l}\text { PITPTNP (0.0001 mol\%) } \\
\text { TाBP (0.18 mol\%o) } \\
\text { Light Source } 2 \mathrm{~h}, 21^{\circ} \mathrm{C}\end{array}$ & $\Rightarrow$ \\
\hline Material & NIR result & Blue result \\
\hline Air & Gel & Gel \\
\hline Water & Gel & Gel \\
\hline Amber Glass & Gel & No Reaction \\
\hline Bacon & Gel & No Reaction' \\
\hline $\mathrm{Ru}(\mathrm{bpy})_{3}\left(\mathrm{PF}_{\mathrm{e}}\right)_{2}(1.5 \mathrm{mM})$ & Gel & No Reaction \\
\hline $700 \mathrm{~nm}$ Long Pass Filter & Gel & No Reaction \\
\hline White Silicone Sheet & Gel & No Reaction \\
\hline 3 Sheets White Paper & Gel & No Reaction \\
\hline Hemoglobin $(0.2 \mathrm{mM})$ & Gel & No Reaction \\
\hline Pig Skin (6.4 mm) & Gel & No Reaction \\
\hline
\end{tabular}
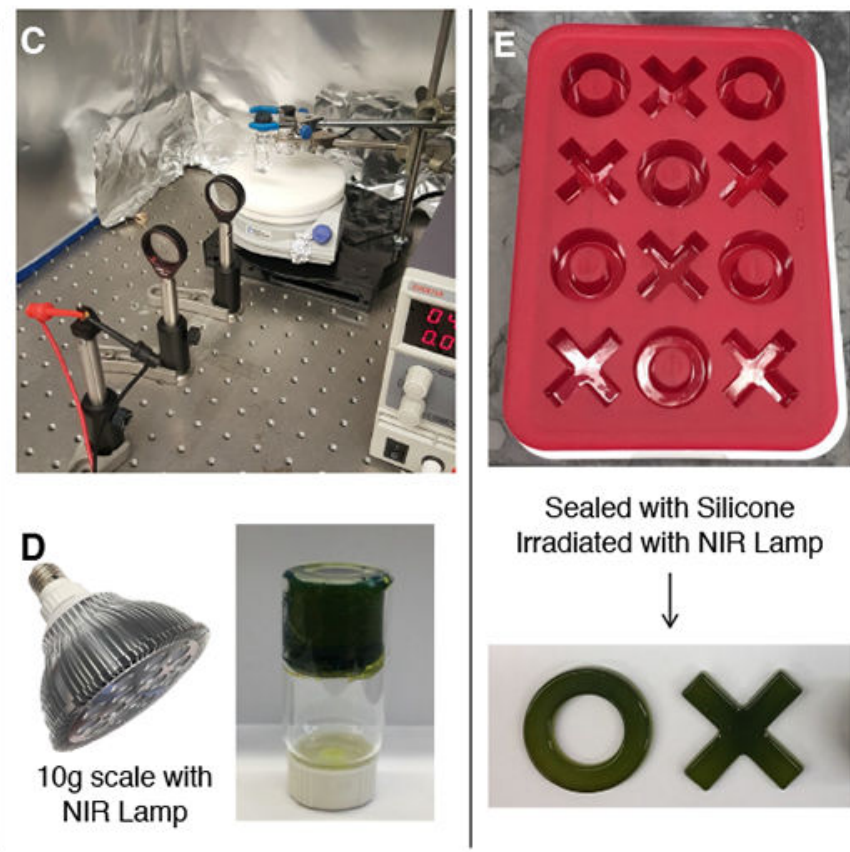

Sealed with Silicone Irradiated with NIR Lamp

Figure 3. Material penetration experiments.

(A) Crosslinked PMMA gel reaction used to test the penetration of NIR $(730 \mathrm{~nm})$ vs blue $(450 \mathrm{~nm})$ light through a variety of media. Reactions which bypass the barrier generate a gel.

$(\boldsymbol{B})$ Table shows results of different materials as light barriers. $(\boldsymbol{C})$ Experimental set up using laser diode, with water as barrier. $(\boldsymbol{D}) 10 \mathrm{~g}$ scale PMMA gel reaction performed with this lamp. (E) Silicone mold used, together with the PMMA shapes that were synthesized through a $7 \mathrm{~mm}$ white silicone pad. 1 . Halted after 15 minutes due to fire hazard with the bacon burning upon irradiation 


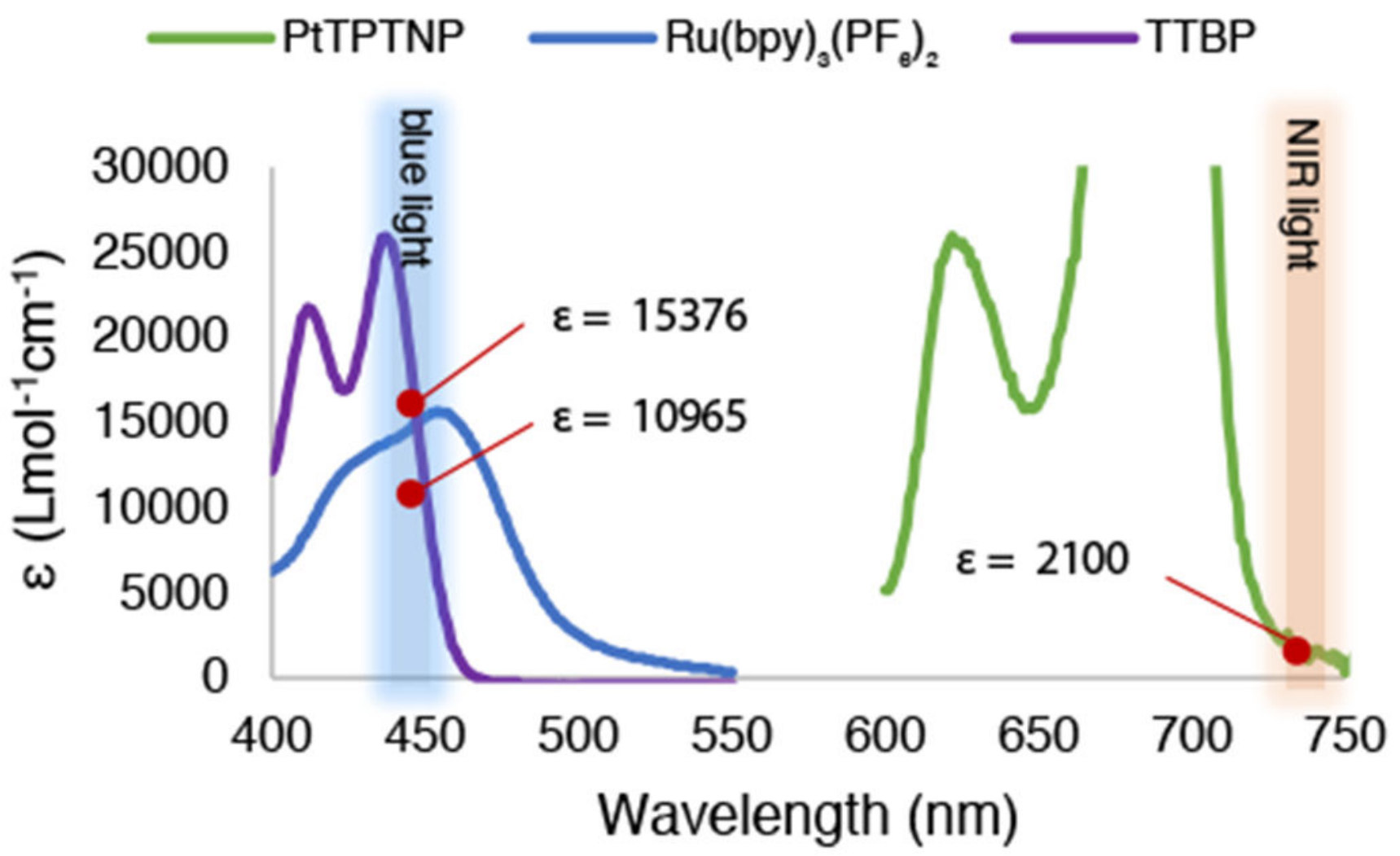

$$
\begin{gathered}
A=\varepsilon \cdot C \cdot L \\
A=\text { absorbance } \\
\varepsilon=\text { extinction coefficient } \\
c=\text { concentration } \\
L=\text { path length }
\end{gathered}
$$

$\mathrm{E} \mathrm{Ru(bpy)})_{3} \varepsilon$ is $7.29 \mathrm{x}$ larger than PtTPTNP

$\mathrm{E} R \mathrm{u}(\mathrm{bpy})_{3} \mathrm{c}$ is $41.7 \mathrm{x}$ larger than PtTPTNP IR penetrates 304 -fold further

$$
\begin{aligned}
& \text { E TTBP } \varepsilon \text { is } 5.17 x \text { larger than PtTPTNP } \\
& \text { E TTBP } c \text { is } 56.7 x \text { larger than PtTPTNP } \\
& \text { IR penetrates } 293 \text {-fold further }
\end{aligned}
$$

Figure 4. Application of the Beer-Lambert law to blue and NIR light.

A comparison of extinction coefficients and concentrations of $\mathrm{Ru}(\mathrm{bpy})_{3}\left(\mathrm{PF}_{6}\right)_{2}$ and TTBP, to those of PtTPTNP reveals 304-fold and 293-fold increase in reaction penetration, according to the Beer-Lambert equation $(A=\varepsilon c L)$, with IR light compared to blue light, respectively. 